\title{
Adult TdT Positive Acute Lymphoblastic Leukemia
}

National Cancer Institute

\section{Source}

National Cancer Institute. Adult TdT Positive Acute Lymphoblastic Leukemia. NCI

Thesaurus. Code C114593.

TdT positive acute lymphoblastic leukemia that occurs during adulthood. 